\title{
Prediction of NDF digestibility based on assumptions about true digestibility and endogenous loss of NDS*
}

\author{
M.R. Weisbjerg', T. Hvelplund and K. Søegaard \\ Danish Institute of Agricultural Sciences, Research Centre Foulum \\ P.O. Box 50, DK-8830 Tjele, Denmark
}

\begin{abstract}
Results from sheep digestibility trials were analysed according to the Lucas principle (Weisbjerg et al., 2004). A true NDS (Neutral Detergent Solubles) digestibility of $101 \%$ and an endogenous loss of $90 \mathrm{~g}$ NDS per kg ingested dry matter (DM) were found.

When organic matter $(\mathrm{OM})$ digestibility is known, this allows a prediction of NDF (Neutral Detergent Fibre) digestibility, as digested OM is equal to the sum of digested NDS and NDF. An evaluation on 2337 observations showed an acceptable prediction of digested NDF in $\%$ of feed DM with no bias.
\end{abstract}

KEY WORDS: neutral detergent fibre, ruminants, digestibility

\section{INTRODUCTION}

Prediction of digestibility of different fractions of the feed cell content based on the chemical analysis is well known (van Soest, 1994). The basis is the socalled Lucas formula. Weisbjerg et al. (2004) estimated a true NDS digestibility of $101 \%$ and an endogenous loss of $90 \mathrm{~g}$ NDS per kg ingested DM.

Digestibility of NDF will become one of the most important feed characteristics in coming feed/ration formulation systems. Therefore, there will be a need for laboratory methods for estimation of NDF digestibility. Fibre does not obey the Lucas principle, and digestibility of NDF can therefore not directly be estimated using this principle. However, as the sum of digested NDS and NDF makes up total digested OM, it should be possible to estimate digestibility of NDF based

\footnotetext{
*Thanks are due to retired colleagues at the Danish Institute of Agricultural Sciences, who have performed a major part of the digestibility trials. We are also grateful for the help from Kjeld Gregersen and Lars Bilde Gildberg

${ }^{1}$ Corresponding author: e-mail: Martin.Weisbjerg@agrsci.dk
} 
on information on OM digestibility and NDF concentration combined with assumptions on NDS true digestibility and endogenous loss.

The aim of the present paper is to present analyses on the prediction of NDF digestibility based on measured OM digestibility and NDF concentration in combination with assumptions on NDS digestibility using the Lucas principle. Data used were from sheep digestibility trials performed in Denmark during the last 18 years.

\section{MATERIAL AND METHODS}

\section{Data}

The digestibility data used are from sheep digestibility trials performed in Denmark from 1984 until now. A total of 5754 digestibility determinations were in the database. However, not all trials involved all chemical analyses on faeces, therefore the data basis for NDS digestibility was 2337 observations after deletion of 73 observations as outliers. These observations covered 504 feed samples. Further 9 straw samples and 2 samples with large residuals (a hay and a maize silage) were omitted, as discussed by Weisbjerg et al. (2004). The analyses were performed on means for feed samples.

Feeds, animals, feeding regime and chemical analyses have been described by Weisbjerg et al. (2004).

\section{Calculations}

NDS was calculated as the difference between OM and NDF.

Based on data from Weisbjerg et al. (2004), apparent NDS digestibility can be estimated as:

Apparent NDS digestibility (\%) $=101.3-[902 / \operatorname{NDS}(\%$ in DM) $]$.

If OM digestibility is known, this allows for estimation of undigested NDF as the difference between undigested OM and undigested NDS:

undigested NDF $(\%$ of feed DM $)=[\mathrm{OM}(\%$ in DM $) \times[100-[\mathrm{OM}$ dig. $(\%)]] /$ $100]$-[NDS $(\%$ in DM $) \times[100$-[apparent NDS dig. (\%)]]/100].

Digested NDF and NDF digestibility can then be calculated:

digested NDF $(\%$ of DM) $=$ NDF $(\%$ in DM $)$ - undigested NDF $(\%$ in DM). NDF digestibility $(\%)=[100 \times[\mathrm{NDF}(\%$ in DM $)]-[$ undigested NDF $(\%$ in DM $)]] /$ [NDF (\% in DM)].

Statistical analyses were performed using SAS 8.02 (SAS, 2001).

\section{RESULTS}

Figures $1 \mathrm{a}$ and $1 \mathrm{~b}$ show predicted digested NDF and predicted NDF digestibility plotted versus measured values. Predicted digested NDF vs measured resulted in an equation very close to $\mathrm{y}=\mathrm{x}$, and with a moderate residual error (root MSE $=2.3$ ). Predicted NDF digestibility resulted in a considerably higher 
residual error, mostly due to small absolute errors become large when digestibility is calculated for feeds where NDF concentration is low. Generally, only minor systematic deviations due to feed type were found.
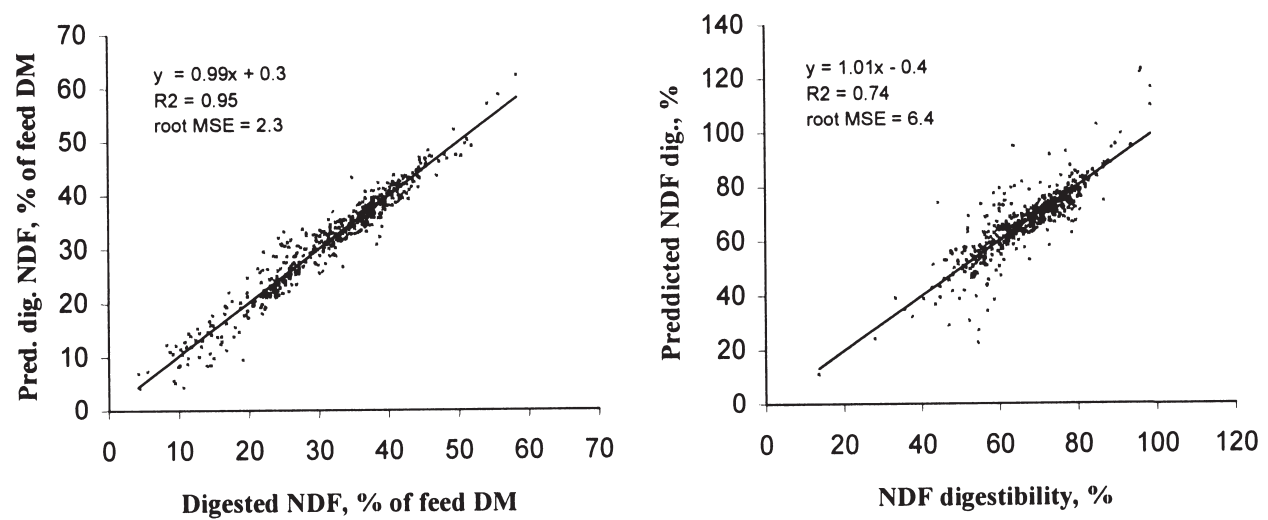

Figure 1. a) Predicted vs measured digested NDF; b) Predicted vs measured NDF digestibility

\section{DISCUSSION}

If we accept the prediction of true digestibility and endogenous loss of NDS based on the Lucas principle, then digestibility of cell wall carbohydrates (NDF) can be predicted from chemical analysis of NDF combined with a determination of organic matter digestibility, as undigested organic matter then is the sum of endogenous loss of cell content and undigested NDF. Analyses on the present material showed, that such prediction of NDF digestibility is possible.

The errors on the prediction of digested NDF are probably to a large degree due to errors on the NDF analysis and to variation on the in vivo digestibility measurements.

This test of NDF digestibility was performed on the same data material as used for estimation of the 'Lucas principle based true digestibility and endogenous loss' of NDS. This could be problematic as the estimated values for true digestibility and endogenous loss of NDS are not independent of the NDF digestibilities. However, the number of observations and the variation in both feed types and chemical composition is so large that the test makes sense despite of the lack of independence.

\section{CONCLUSIONS}

A method has been presented for the estimation of NDF digestibility of a feed based on OM digestibility and NDF concentration, which are both common feed analyses. The method seems to be valid across typical ruminant feedstuffs. The 
estimated digestibility should be interpreted as expected digestibility in sheep fed on maintenance level, and the digestibility is in principle apparent, however, as endogenous losses should not contain NDF, it can also be regarded as true NDF digestibility.

In future ration/feed evaluation systems NDF digestibility in sheep fed at maintenance level will probably be of minor interest. However, these digestibilities, eventually in combination with other laboratory measures, could be used for a subsequent estimation of potential NDF digestibility and rate of NDF degradation, two characteristics which with no doubt will be extremely important in the coming ration/feed evaluation systems. Further, NDF digestibility is an important factor in plant breeding, where the presented method could be used.

\section{REFERENCES}

Lucas H.L., 1964. Stochastic elements in biological models; their sources and significance. In: J. Gurland (Editor). Stochastic Models in Medicine and Biology. University Wisconsin Press, Madison, pp. 355. cf. van Soest, 1994

SAS, 2001. Release 8.02. SAS Institute Inc. Cary, NC

Van Soest P.J., 1994. Nutritional Ecology of the Ruminant. 2. Edition. Cornell University Press, Ithaca, pp. 476

Weisbjerg M.R., Hvelplund T., Søegaard K., 2004. Prediction of digestibility of neutral detergent solubles using the Lucas principle. J. Anim. Feed Sci. 13, Suppl. 1, 239-241 